\title{
VHDL Implementation of Fast Multiplier based on Vedic Mathematic using Modified Square Root Carry Select Adder
}

\author{
Heena Goyal \\ Department Of Electronics, IGIT, GGSIP \\ University, Delhi, India.
}

\author{
Shamim Akhter, PhD \\ Assistance Professor, ECE Department \\ Jaypee Institute of Information Technology, India
}

\begin{abstract}
In this paper, a novel technique for multiplication is presented using Vedic multiplier. Vedic multiplier uses adders and hence making fast adder will increase the overall speed for multiplication. We have done comparative analysis for multiplication using different architectures of adder. For comparison we have taken Carry Select Adder (CSA), Square Root Carry Select Adder (SQRT-CSA). We have proposed Vedic multiplication using Modified SQRT-CSA. VHDL design in proposed and synthesis is performed on Virtex-4 FPGA.
\end{abstract}

\section{Keywords}

Vedic Multiplier, CSA, SQRT-CSA, Modified SQRT-CSA, Binary-to Excess One (BEC) block

\section{INTRODUCTION}

Many digital signals processing operation requires several multiplication and for the same we need fast multipliers. This paper presents a systematic design methodology for fast and area efficient multiplier based on Vedic mathematics [1].The Multiplier Architecture is based on the Vertical and Crosswise algorithm of ancient Indian Vedic Mathematics. The adder block used during Vedic Algorithm based computation is main source of delay. We have compared multiplication operation different topologies of adder like Ripple Carry Adder (RCA), Carry Look-ahead Adder (CLA), Carry Select Adder (CSA), Square Root CSA (SQRT-CSA) and modified SQRT-CSA.

The organization of this paper is as follows. Section-I present logic for Vedic Algorithm based multiplication operation. Section-II deals with the analysis of Adder using different topologies. Section -III deals with analysis and designing of modified SQRT-CSA. Section-IV deals with the simulation and synthesis results followed by conclusion and references.

\section{VEDIC ALGORITHM BASED MULTIPLICATION}

The VHDL design of Vedic multiplier is proposed in [1]. It represents the modular design. The basic module is $2 \times 2$ multiplier. Using this module, the paper [1] presents the design of $4 \times 4$ multiplier based on Vedic logic. Let's analyze $4 \times 4$ multiplications of $A$ and $B$, each of 4-bits. Taking $A=$ $\mathrm{A}_{3} \mathrm{~A}_{2} \mathrm{~A}_{1} \mathrm{~A}_{0}$ and $\mathrm{B}=\mathrm{B}_{3} \mathrm{~B}_{2} \mathrm{~B}_{1} \mathrm{~B}_{0}$ and the multiplication result as,

$\mathrm{S}_{7} \mathrm{~S}_{6} \mathrm{~S}_{5} \mathrm{~S}_{4} \mathrm{~S}_{3} \mathrm{~S}_{2} \mathrm{~S}_{1} \mathrm{~S}_{0}$. Divide $\mathrm{A}$ and $\mathrm{B}$ into two parts as $\mathrm{A}_{3} \mathrm{~A}_{2}$ and $A_{1} A_{0}$ for $A$ and $B_{3} B_{2}$ and $B_{1} B_{0}$ for $B$. Using the fundamental of Vedic multiplication, taking two bit at a time and using 2bit multiplier block, we can have the following structure for multiplication.

$$
\mathrm{A}_{3} \mathrm{~A}_{2} \mathrm{~A} 1 \mathrm{~A} 0
$$

$\mathrm{X} \mathrm{B}_{3} \mathrm{~B}_{2} \mathrm{~B} 1 \mathrm{~B} 0$

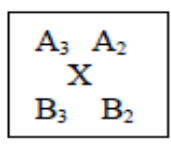
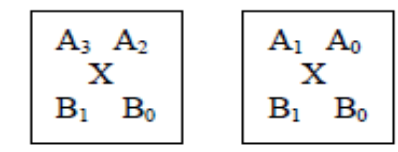

$$
\begin{aligned}
& \mathrm{A}_{1} \quad \mathrm{~A}_{0} \\
& \mathrm{~B}_{3} \quad \mathrm{~B}_{2}
\end{aligned}
$$

Figure 1. Block diagram for $4 \times 4$ bit multiplication [1]

The outputs of first $2 \times 2$ multiplier block with inputs $\mathrm{A}_{1} \mathrm{~A}_{0}$ and $\mathrm{B}_{1} \mathrm{~B}_{0}$ are taken $\mathrm{S}_{\text {temp13 }} \mathrm{S}_{\text {temp } 12} \mathrm{~S}_{\text {temp11 }} \mathrm{S}_{\text {temp } 10}$.

The outputs of last $2 \times 2$ multiplier block with inputs $\mathrm{A}_{3} \mathrm{~A}_{2}$ and $\mathrm{B}_{3} \mathrm{~B}_{2}$ are taken $\mathrm{S}_{\text {temp } 43} \mathrm{~S}_{\text {temp } 42} \mathrm{~S}_{\text {temp } 41} \mathrm{~S}_{\text {temp } 40}$.

We have remaining two blocks of $2 \times 2$ Multiplier. First block with inputs $\mathrm{A}_{3} \mathrm{~A}_{2}$ and $\mathrm{B}_{1} \mathrm{~B}_{0}$ and having output as $\mathrm{S}_{\text {temp23 }} \mathrm{S}_{\text {temp22 }} \mathrm{S}_{\text {temp21 }} \mathrm{S}_{\text {temp20 }}$. Second block with inputs $\mathrm{A}_{1} \mathrm{~A}_{0}$ and $B_{3} B_{2}$ and having output as $S_{\text {temp33 }} S_{\text {temp32 }} S_{\text {temp31 }} S_{\text {temp30 }}$.

The final multiplication result in 8 bit i.e. $S_{7} S_{6} S_{5} S_{4} S_{3} S_{2} S_{1} S_{0}$ is obtained as discussed below [1].

Two LSB bits of first $2 \times 2$ bit Multiplier output i.e. $S_{\text {temp11 }}$ and $S_{\text {temp10 }}$ forms the result bits $S_{1}$ and $S_{0}$ respectively.

A 4-bit full adder is used to add $S_{\text {temp23 }} S_{\text {temp22 }} S_{\text {temp21 }} S_{\text {temp20 }}$ and $\mathrm{S}_{\text {temp33 }} \mathrm{S}_{\text {temp32 }} \mathrm{S}_{\text {temp31 }} \mathrm{S}_{\text {temp30 }}$ with carry out from this addition as $\mathrm{C}_{\text {out } 1}$. The result of this addition is given as one set of 4- bit input to the next adder with the $2^{\text {nd }}$ set of input as $\mathrm{S}_{\text {temp41 }} \mathrm{S}_{\text {temp40 } 0} \mathrm{~S}_{\text {temp13 }} \mathrm{S}_{\text {temp12 }}$. Carry out from this addition is taken as $\mathrm{C}_{\text {out2 }}$ with sum as final result bits $\mathrm{S}_{5} \mathrm{~S}_{4} \mathrm{~S}_{3} \mathrm{~S}_{2}$.

The carry out signals $\mathrm{C}_{\text {out } 1}$ and $\mathrm{C}_{\text {out } 2 \text { is }}$ given to half adder and the outputs of this half adder is taken as $\mathrm{C}_{\text {out } 3} \mathrm{~S}_{\text {temp5 }}$. The carry and sum from the half adder i.e. $\mathrm{C}_{\text {out3 } 3} \mathrm{~S}_{\text {temp5 }}$ form one set of input of 2-bit full adder with second set of input as $\mathrm{S}_{\text {temp43 }}$ and $S_{\text {temp42 }}$ gives the remaining result bit as $S_{7} S_{6}$.

The above logic can be extended for higher order bits in input and the same is explained below.

For NxN multiplication, divide the multiplicand and multiplier into two parts, consisting of ( $\mathrm{N}$ to $\mathrm{N} / 2-1)$ bits and (N/2 to 1) bits. For example, for multiplication of $A$ and B, of 16 bit each, if $A=0000001010101101$, then its part will be 00000010, and 10101101. Similarly divided B is equal parts, i.e. if $\mathrm{B}=0010001110101011$, then its part will be 00100011 and 10101011. Represent the above mentioned parts of A as 
$A_{M}$ and $A_{L}$. Similarly for the input $B$, it is divided in two parts as $B_{M}$ and $B_{L}$. Now represent $A$ and $B$ as $A_{M} A_{L}$ and $B_{M} B_{L}$. For AXB, we can have

$$
\begin{aligned}
& A_{M} A_{L} \\
& \mathrm{~B}_{\mathrm{M}} \mathrm{B}_{\mathrm{L}} \\
& A_{M} \times B_{M}\left|\begin{array}{c}
A_{M} \times B_{L} \\
A_{L} \times B_{M}
\end{array}\right| A_{L} \times B_{L}
\end{aligned}
$$

Figure 2. General representation for Vedic multiplication [1]

Let's say, the overall result is to be represented in $S_{31} S_{30 \ldots . . .} S_{1}$ $\mathrm{S}_{0}$. The output of partial product $\mathrm{A}_{\mathrm{M}} \times \mathrm{B}_{\mathrm{M}}$, is $\mathrm{S}_{\mathrm{MM} 15} \mathrm{~S}_{\mathrm{MM} 14} \ldots \ldots$ $\mathrm{S}_{\mathrm{MM} 1} \mathrm{~S}_{\mathrm{MM} 0}$. Similarly the outputs of partial products for $A_{M} \mathrm{X}$ $\mathrm{B}_{\mathrm{L}}, \mathrm{A}_{\mathrm{L}} \times \mathrm{B}_{\mathrm{M}}$, and $\mathrm{A}_{\mathrm{L}} \times \mathrm{B}_{\mathrm{L}}$, are taken as $\mathrm{S}_{\mathrm{ML} 15} \ldots \ldots . . \mathrm{S}_{\mathrm{ML} 0}$,

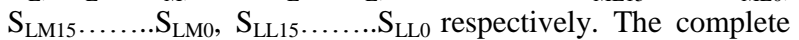
block diagram for the same is given below [1].

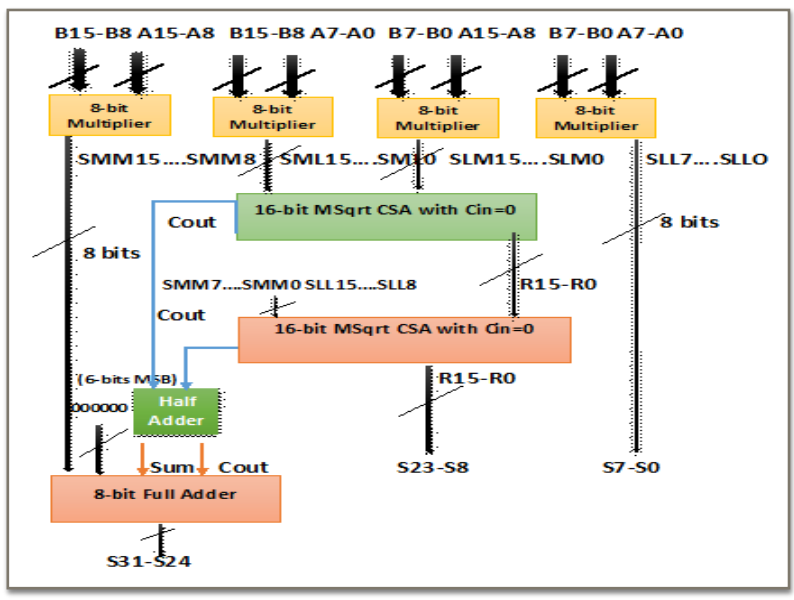

Figure 3. Block Diagram for 16-bit Multiplication Using Vedic Multiplication [1]

\section{DIFFERENT TOPOLOGIES FOR ADDER}

In our work, we have analyzed the multiplication architecture by using different topologies of adder. We have considered Ripple Carry Adder (RCA), Carry Look-ahead Adder (CLA), CSA, SQRT-CSA [2-4]. In this work, we have proposed Vedic multiplication by using modified SQRT-CSA adder. RCA and CLA are basic adders and can be found in literature very well. In next sub-section, we have explained the working of CSA and SQRT-CSA since it is the basic of Modified SQRT-CSA.

\subsection{Working of Carry Select Adder (CSA)}

The carry-select adder consists of two ripple carry adders and a set of multiplexers. The block diagram for 4-bit addition using CSA is given in Figure 4. For adding two 4-bit numbers using CSA, we require two 4-bit full adders and that can be Ripple Carry Adder (RCA) or Carry Look-Ahead Adder (CLA). $1^{\text {st }}$ stage computes the 4 -bit addition using $\mathrm{Cin}=0$ and $2^{\text {nd }}$ stage computes the same with $\mathrm{Cin}=1$. After the two results are available, the correct sum and carry out is then decided by the multiplexer once the correct carry is known [4]. For designing 16-bit adder, we can cascade the structure shown in Figure.4. It means we need four stages of CSA to create 16-bit CSA adder. The number of bits in each CSA block is uniform. It is made variable in case of SQRT-CSA to get optimal delay [4].

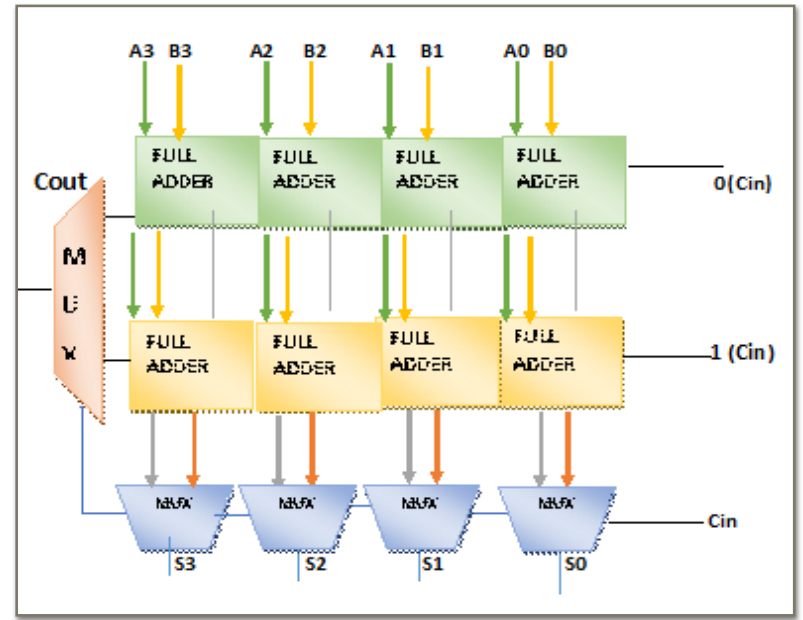

Figure 4. Block Diagram for 4-bit CSA

\subsection{Working of Square-Root Carry Select Adder (SQRT-CSA)}

A 16-bit CSA with variable size is created by cascading four CSA with variable input size. The block diagram for the same is given below.

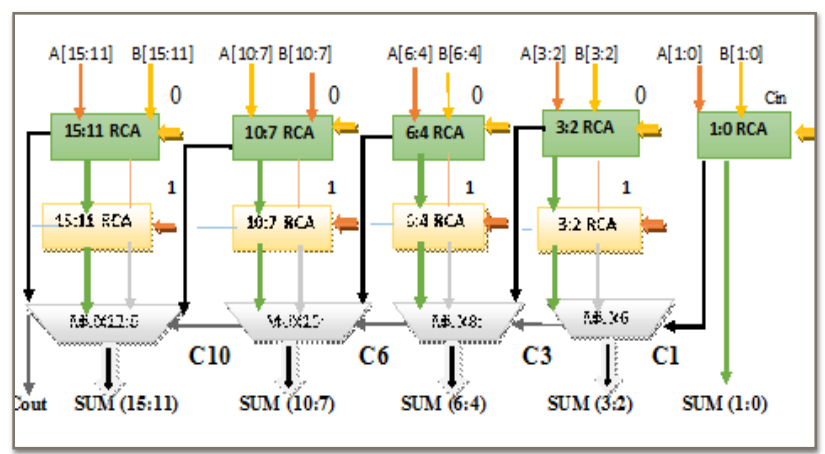

Figure 5. Block Diagram for 4-bit SQRT-CSA [5]

As shown in Figure.5, we have five stages of CSA with different inputs bits to each stage. We have an adder with block sizes of 2-2-3-4-5 respectively. In the above structure the adder module with $\mathrm{Cin}=1$ is replaced with BEC (BinaryTo-Excess one) module [2, 5]. This design was named Modified QSRT-CSA [2, 5]. The analysis for the same is given in next section.

\section{ANALYSIS AND DESIGNING OF MODIFIED SQRT-CSA}

Conventional CSA with Cin=1 block is replaced with binaryto-excess-1 converter (BEC) in the modified SQRT CSA structure. The architecture of 16-bit CSA is configured into five different stages with progressively increasing data size as given in Figure.5. The design steps for 4-bit BEC block is discussed in next section. The design can be extended for other bit size easily.

\subsection{Binary-to-Excess-1 Converter (BEC)}

This block is responsible for adding one (' 1 ') to the input data so that the RCA with Cin=1 can be replaced. The design for the same is explained below for 4-Bit BEC block which takes four inputs and delivers four bit output. 
Table 1: 4-Bit BEC Truth Table

\begin{tabular}{|l|l|l|l|l|l|l|l|}
\hline \multicolumn{5}{|c|}{ Input } & \multicolumn{4}{l|}{ Output } \\
\hline $\mathrm{B}_{3}$ & $\mathrm{~B}_{2}$ & $\mathrm{~B}_{1}$ & $\mathrm{~B}_{0}$ & $\mathrm{X}_{3}$ & $\mathrm{X}_{2}$ & $\mathrm{X}_{1}$ & $\mathrm{X}_{0}$ \\
\hline 0 & 0 & 0 & 0 & 0 & 0 & 0 & 1 \\
\hline 0 & 0 & 0 & 1 & 0 & 0 & 1 & 0 \\
\hline 0 & 0 & 1 & 0 & 0 & 0 & 1 & 1 \\
\hline$\cdot$ &. &. &. &. &. &. &. \\
\hline$\cdot$ &. &. &. &. &. &. &. \\
\hline 1 & 1 & 1 & 1 & 0 & 0 & 0 & 0 \\
\hline
\end{tabular}

The Boolean expressions for $\mathrm{X}_{0}, \mathrm{X}_{1}, \mathrm{X}_{2}$ and $\mathrm{X}_{3}$ as derived from K-Map are:

$\mathrm{X}_{0}=\operatorname{NOT}\left(\mathrm{B}_{0}\right)$

$\mathrm{X}_{1}=\operatorname{XOR}\left(\mathrm{B}_{0}, \mathrm{~B}_{1}\right)$

$\mathrm{X}_{2}=\mathrm{XOR}\left[\mathrm{B}_{2},\left(\mathrm{~B}_{0} \mathrm{AND} \mathrm{B}_{1}\right)\right]$

$\mathrm{X}_{3}=\mathrm{XOR}\left[\mathrm{B}_{3},\left(\mathrm{~B}_{0}\right.\right.$ AND B $\left.\left.\mathrm{AND} \mathrm{B}_{2}\right)\right]$

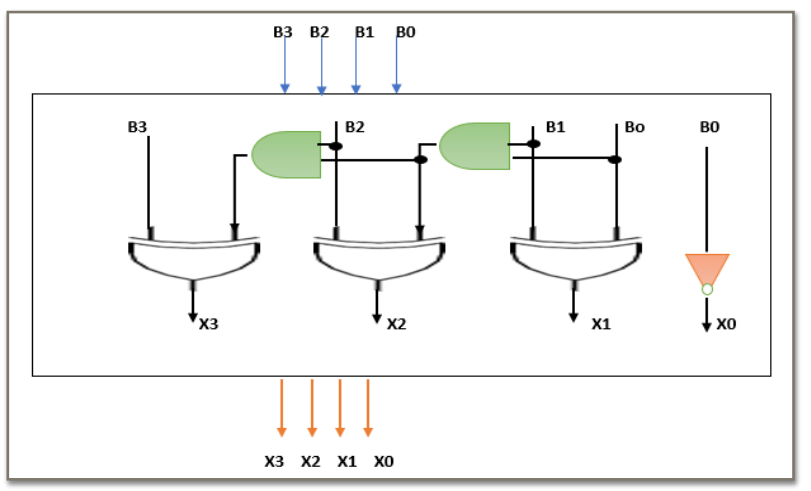

Figure 6: 4-bit binary-to-excess-1 converter [2]

This design can be extended for differnt input size length.

\subsection{6-bit Modified SQRT-CSA}

The complete block diagram for 16-bit Modified SQRT-CSA based on BEC is shown in Figure 7. The components used in the above designed is coded in VHDL and using structural modelling all block are combined. The BEC input bits are output of adder stage with Cin='0'. For example, for 4-Bit BEC, inputs are $\{$ cout $\operatorname{sum}(6) \operatorname{sum}(5) \operatorname{sum}(4)\}$ of 3 rd stage. Similarly for 5-Bit BEC, inputs are \{cout $\operatorname{sum}(10) \operatorname{sum}(9)$ $\operatorname{sum}(8) \operatorname{sum}(7)\}$ of 4 th stage.

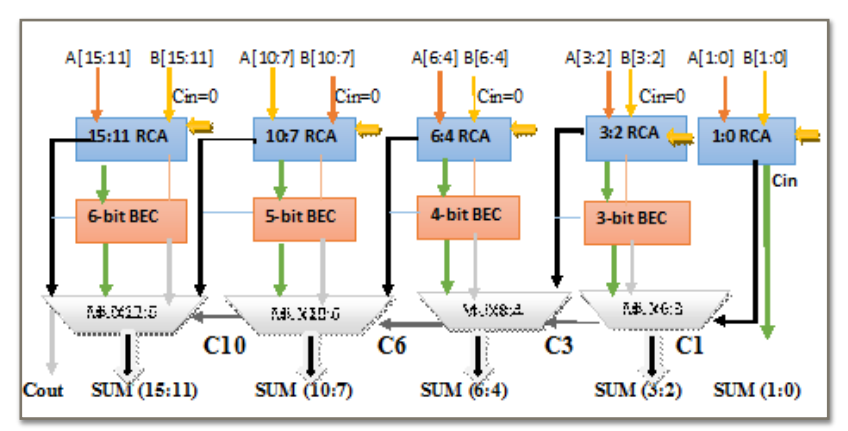

Figure 7: Block diagram of modified 16-bit SQRT CSA [2]

\subsection{6-bit Multiplier based on Vedic Logic using Modified SQRT-CSA}

As shown in Figure.1, the $4 \times 4$ bit multiplication requires basic $2 \times 2$ multiplier. In addition to this, Vedic multiplication requires two 4-bit Full Adder, and one Half Adder and One 2bit adder. The Table 2 given below shows the design requirements for the higher order multiplication in terms of input bit size.

Table 2: Design requirements for different input bit length

\begin{tabular}{|c|c|c|c|c|}
\hline Multiplication & Multiplier & \multicolumn{3}{|c|}{ Adder Requirements } \\
\hline $4 \times 4$ & $2 \times 2$ & $\begin{array}{l}\text { Two, } \\
\text { 4-bit FA }\end{array}$ & $\begin{array}{l}\text { One, } \\
\text { 2-bit FA }\end{array}$ & $\begin{array}{l}\text { One, } \\
\text { HA }\end{array}$ \\
\hline $8 \times 8$ & $4 \times 4$ & $\begin{array}{l}\text { Two, } \\
\text { 8-bit FA }\end{array}$ & $\begin{array}{l}\text { One, } \\
\text { 4-bit FA }\end{array}$ & $\begin{array}{l}\text { One, } \\
\text { HA }\end{array}$ \\
\hline $16 \times 16$ & $8 \times 8$ & $\begin{array}{l}\text { Two, } \\
\text { 16-bit } \\
\text { FA }\end{array}$ & $\begin{array}{l}\text { One, } \\
\text { 8-bit FA }\end{array}$ & $\begin{array}{l}\text { One, } \\
\text { HA }\end{array}$ \\
\hline $32 \times 32$ & $16 \times 16$ & $\begin{array}{l}\text { Two, } \\
\text { 32-bit } \\
\text { FA }\end{array}$ & $\begin{array}{l}\text { One, } \\
\text { 16-bit FA }\end{array}$ & $\begin{array}{l}\text { One, } \\
\text { HA }\end{array}$ \\
\hline
\end{tabular}

Since the advantages of CSA, SQRT-CSA and Modified SQRT-CSA in terms of delay is visible for large sizes of input bit length. We have designed the $4 \times 4,8 \times 8,16 \times 16$ and $32 \times 32$ bit multiplication based on Vedic multiplier using different topologies of adder i.e. CLA, CSA, SQRT-CSA and Modified SQRT-CSA. The simulation is performed in ModelSim and synthesis is done using Xilinx for Vertex 4 (ML 402).

\section{SIMULATION AND SYNTHESIS RESULTS}

Simulation is performed for different set of input data. Simulation waveform from ModelSim simulator can't be pasted due to large no of signal count. So we have given the equivalent numeric values for two sets of input data.

1st set of input data and result

Input A: 0000110010111100 (3260),

Input B: $0000000001000011(67)$,

Result: 00000000000000110101010100110100 (218420)

2nd set of input data and result

Input A: 0000010010110000 (1200),

Input B: $0010000001000011(8259)$,

Result: 00000000100101110011101000010000 (9910800)

The synthesis result is tabulated for 8-bit, 16-bit and 32-bit Vedic multiplier based on CLA, CSA, SQRT-CSA, and MSQRT-CSA. 
Table 3: Synthesis Result Comparison 8-bit Multiplication

\begin{tabular}{|l|l|l|l|}
\hline $\begin{array}{l}\text { Topologies for 8-bit } \\
\text { Vedic Multiplier }\end{array}$ & Delay(ns) & $\begin{array}{l}\text { No of } \\
\text { Slices }\end{array}$ & $\begin{array}{l}\text { No of } \\
\text { LUT's }\end{array}$ \\
\hline CLA & 17.567 & 93 & 162 \\
\hline CSA & 18.240 & 126 & 224 \\
\hline SQRT-CSA & 20.129 & 120 & 213 \\
\hline MSQRT-CSA & 20.213 & 124 & 221 \\
\hline
\end{tabular}

Table 4: Synthesis Result Comparison 16-bit Multiplication

\begin{tabular}{|l|l|l|l|}
\hline $\begin{array}{l}\text { Topologies for 16-bit } \\
\text { Vedic Multiplier }\end{array}$ & Delay(ns) & $\begin{array}{l}\text { No of } \\
\text { Slices }\end{array}$ & $\begin{array}{l}\text { No of } \\
\text { LUT's }\end{array}$ \\
\hline CLA & 30.216 & 411 & 716 \\
\hline CSA & 28.528 & 541 & 969 \\
\hline SQRT-CSA & 31.056 & 538 & 954 \\
\hline MSQRT-CSA & 29.867 & 557 & 990 \\
\hline
\end{tabular}

Table 5: Synthesis Result Comparison 32-bit Multiplication

\begin{tabular}{|l|l|l|l|}
\hline $\begin{array}{l}\text { Topologies for 32-bit } \\
\text { Vedic Multiplier }\end{array}$ & Delay(ns) & $\begin{array}{l}\text { No of } \\
\text { Slices }\end{array}$ & $\begin{array}{l}\text { No of } \\
\text { LUT's }\end{array}$ \\
\hline CLA & 55.772 & 2040 & 3574 \\
\hline CSA & 47.349 & 2368 & 4216 \\
\hline SQRT-CSA & 53.037 & 2229 & 3950 \\
\hline MSQRT-CSA & 47.173 & 2362 & 4194 \\
\hline
\end{tabular}

It can be seen that Vedic multiplication based on MSQRTCSA is more efficient as compared to CSA and SQRT-CSA in terms of delay.

\section{CONCLUSION}

In this paper, a fast technique of digital multiplication is presented using Modified SQRT-CSA. The design is based on Vedic method of multiplication and adder is the main component for the delay. Hence we have done delay analysis of multiplication with different adder topologies and come to conclusion that Modified SQRT-CSA based multiplication is fast. Due to modular design approach complexity gets reduced for large inputs bit length.

\section{REFERENCES}

[1] Shamim Akhter, "VHDL Implementation of Fast NxN Multiplier Based on Vedic Mathematic," Proc. of 18th European Conference on Circuit Theory and Design (ECCTD), pp. 472-475, Aug. 2007.

[2] Y. He, C.H. Chang, and J. Gu, "An Area Efficient 64-Bit Square Root Carry-Select Adder for Low Power Applications," Proc. of IEEE International Symposium on Circuits and Systems (ISCAS-2005), vol. 4, pp. 4082 4085, May 2005.

[3] N. H. E. Weste, D. Harris, and A. Banerjee, "CMOS VLSI Design: A Circuits and Systems Perspective," Pearson Education, $3^{\text {rd }}$ Edition, 2005.

[4] B. Ramkumar, and H. M. Kittur, "Low-Power and AreaEfficient Carry Select Adder," IEEE Transactions on Very Large Scale Integration (VLSI) Systems, vol. 20, no. 2, pp. 371-375, Feb. 2012.

[5] Shamim Akhter, S. Chaturvedi, and K.Pardhasardi, "CMOS Implementation of Efficient 16-Bit Square Root Carry-Select Adder,“ 2nd International Conference on Signal Processing and Integrated Networks (SPIN), India, Noida, pp. 891 - 896, Feb 2015.

[6] G.Singh , "Design of Low Area and Low Power Modified 32-BIT Square Root Carry Select Adder", International Journal of Engineering Research and General Science Volume 2, Issue 4, 2014, pp-422-431. 